\title{
Can Teachers' Burnout Explain Students' Engagement In The Physical Education Context? A Multi-Level Analysis through A Self-Determination Lens
}

\author{
Javier Coterón ${ }^{1}$, Javier Gil ${ }^{1}$ \& Evelia Franco ${ }^{2}$ \\ ${ }^{1}$ Universidad Politécnica de Madrid, Madrid (Spain) \\ ${ }^{2}$ Universidad Pontificia Comillas, Madrid (Spain)
}

\begin{abstract}
Students' engagement in physical education (PE) has traditionally drawn much attention from the research community in educational practices. The reason for such interest might be the relationship between students' engagement and several adaptive consequences. The existing literature suggests that certain students' motivational variables like basic psychological needs (BPN) satisfaction can predict engagement. Unfortunately, research is scarce on how teachers' antecedents might influence this behavioural outcome. This study seeks to analyse the influence of teachers' burnout experience on their students' behavioural engagement and on the relationship between students' BPN and behavioural engagement. The sample included 28 PE teachers and 644 students who were taught by the participant teachers. Data were collected using both papers and online surveys and they were analysed using multilevel modelling techniques. The results revealed that teachers' burnout experience might negatively influence students' engagement $(\beta=-0.19, \mathrm{p}<0.05)$. Furthermore, students' BPN satisfaction did also predict students' behavioural engagement $\left(\beta_{\text {autonomy }}=0.21, \mathrm{p}<0.01\right.$; $\left.\beta_{\text {competence }}=0.34, \mathrm{p}<0.01 ; \beta_{\text {relatedness }}=0.08, \mathrm{p}<0.05\right)$. Lastly, teachers' burnout did not seem to affect the association between the students' basic psychological needs and behavioural engagement. These findings highlight the impact of teachers' emotional states on their students' experience in the PE class. Results are discussed in terms of teachers' external pressures which could undermine teachers' wellbeing, and in turn, could affect relevant students' outcomes.
\end{abstract}

Keywords: adolescents; basic psychological needs; hierarchical models; teaching practices 